\title{
English Language Teacher Agency in Rural Sarawak: Exploiting Teaching Materials
}

\author{
Tamas Kiss \\ Centre for English Language Studies \\ Sunway University, Malaysia \\ Hazelynn Rimbar \\ Freelance Educational Consultant, Malaysia
}

\begin{abstract}
This paper explores English language teacher agency in rural Sarawak, Malaysia within the context of materials exploitation. The introduction of an international textbook series in all primary schools in Malaysia has brought about significant challenges for teachers who work in socially and economically deprived educational settings, where resources are scarce and where the textbook's cultural references may be alien to the learners. In order for it to be meaningfully used in the classroom, language teachers need to adapt and localize the textbook for their learners. However, diverting from the officially prescribed material and scheme of work may be a risky business and it requires high levels of teacher autonomy and agency. The data show that although research participants find the materials in need of adaptation, not all make changes due to possible deficiencies in their capabilities or their lack of willingness to act. Those who make changes and thus enact their professional beliefs and values are motivated by completely different reasons. The study found that teachers' interpretation of their work context significantly influences their agential roles and that teacher agency emerges from an interaction of individual capability, professional action, and the professional and social contexts in which the teacher operates.
\end{abstract}

KEYWORDS: Teacher agency, textbooks, teaching materials, materials adaptation

\section{Introduction}

There is a substantial amount of professional literature on how language teaching materials can be adopted, adapted, and exploited in the classroom, but relatively little is written about how teachers actually use materials (Kiss \& Rimbar, 2017; Tomlinson, 2012). This is more of a mystery in areas where the national curriculum dictates teaching materials which are culturally and socio- 
economically removed from the contexts in which they are employed. Such is the case in rural Sarawak, where the Malaysian Ministry of Education mandated language teaching textbooks which are deemed difficult to implement due to their cultural content (Kiss \& Rimbar, 2017). The fact, that a significant gap exists between the local students' knowledge of the world and the reality that the mandatory textbooks present, puts teachers in a difficult position. Should they adapt the materials and supplement them with locally relevant and familiar texts that would make learning meaningful for the students, or should they focus on the linguistic content of the books in an attempt to prepare their learners for oncoming examinations?

This paper focuses on the above dilemma English language teachers in rural Sarawak, a socioeconomically challenged region of Malaysia, face every day in their resources-deprived classrooms. Through a questionnaire survey and a series of in-depth interviews with selected participants, the authors aimed to explore how teachers take initiatives to make a culturally alien teaching material more relatable for their learners. The data indicate that teachers realize the mismatch of the materials for the local context, and to some extent, they feel empowered to make changes they deem necessary. However, the reasons for enacting agentive roles and explore new pathways are clearly influenced by an examination culture (Cheah, 1988; Kiss \& Mizusawa, 2018) that strangles grassroot educational innovations in many countries. The view that "we need teaching materials to save learners from our deficiencies as teachers" (Allwright, 1981, p. 6) should be put to rest and replaced by 'we need teachers to save learners from the deficiencies of an examination system'.

\section{What is Teacher Agency?}

Teacher agency, i.e. the ability of teachers to actively enact their educational beliefs, values in a principled manner, is an important field of current ELT research. Yet, teacher agency is not a concept that can be defined easily as it stems from the different interpretations of human agency in general. According to Goller and Paloniemi (2017), there are two types of agency discussed in the professional literature; either it is seen as an individual characteristic, or as something that originates from action related to personal or professional activities. Bandura (2001, p. 1), for example, defines agency as a capacity of humans to "exercise control over the nature and quality of one's life". Another interpretation emphasizes not this capacity, from which particular action may never realize, but the active decision-making processes and the enactment of those decisions in one's professional roles (Eteläpelto, Vähäsantanen, Hökkä, \& Paloniemi, 2013).

Further definitions of teacher agency build on the interaction of the individual (including both capacity and action) and the contexts in which professional roles are performed (Biesta \& Tedder, 2007; Imants \& Van der Wal, 2020). This view of agency blends in with an ecological perspective of teaching and is not far from the conceptual framework of Complex Dynamics Systems Theory which posits that elements of a system are interconnected in a non-linear and dynamic manner, and rely on feedback from within and input from outside to flourish. This theory also holds that initial conditions can have an impact on how the system reacts and small changes often lead to disproportionate results (see for example, Gleick, 1987; Larsen-Freeman, 1997, 2002; Van Lier, 2010). In other words, the whole - i.e. teacher agency - is always more than the composite parts from what it is formed. 
This argument is similar to Sealey and Carter's (2004, p. 12) definition of teacher agency in which they view it as "an 'emergent property' [...] generated from its constituent elements, but is not reducible to them". For them, the elements that teacher agency is constructed from are selfconsciousness, reflexivity, intentionality, cognition, and emotionality. The definition, however, focuses more on the individual than on the individual's interaction with the context. Therefore, in this paper, we will use Bouchard's (2017, p. 92) definition that specifies teacher agency as "people's actions and motivations emerging from their interaction with cultural and structural forces in their attempts to fulfil particular goals and objectives" since it gives a central role to the interconnectedness of both individual capacity and the professional and social contexts in which the agentive role is enacted.

\section{Agency and Professional Identity}

There is no doubt that teacher agency and professional identity are closely related concepts. Since teacher agency partly stems from personal factors, it seems valid to cite Archer (2003, p. 120): "who we are is a matter of what we care about and the commitments we make accordingly". Therefore, in our professional capacities, we define ourselves through our choices and actions, which are influenced by knowledge, values, and beliefs, or more generally speaking, by teacher cognition (Borg, 2006). Furthermore, commitments teachers make serve as an indication of their motivation for improvement, let that be their own professional development or the improvement of learning and/or the learning conditions of their charges.

Borg's (2006) teacher cognition model, in fact, bears some similarities to conceptualizations of teacher agency. This is not surprising; how we act (or choose not to act) is strongly influenced by our experiences as learners and teachers, our socialization into teaching, and the various experiences collected as teachers. Therefore, agency depends on and is informed by many factors, including both present and past, personal and professional experiences (Priestley, Biesta, \& Robinson, 2015).

\section{The Importance of Context}

Contexts in which teachers enact their agentive roles are instrumental in either supporting or suppressing autonomy, as well as action. Biesta and Tedder (2007, p. 137) point out that "actors always act by means of their environment rather than simply in their environment" and add that "the achievement of agency will always result from the interplay of individual efforts, available resources and contextual and structural factors as they come together in particular and, in a sense, always unique situations". This explains why teachers in certain contexts find it easier to conduct themselves in a professionally independent manner whereas in another context they subscribe to what Leung (2009) calls "sponsored professionalism", i.e. the dominant views of education held and enforced by powerful stakeholders. This suggests that although teachers may have the capacity for agency, they might find it "too difficult, or too risky to enact" (Priestley et al., 2015, p. 7). 
Holliday (2015, p. 21), on the other hand, is more optimistic. Although he acknowledges the difficulty some teachers may face due to contextual constraints, he argues that "this does not mean that they are culturally confined by them and do not have the potential to act when there is the opportunity." In fact, looking at contextual limitations and boundaries as completely outside of teachers' control is not an accurate representation of the issue (Imants \& Van der Wal, 2020). Furthermore, when teacher agency is viewed in an ecological, complex dynamic systems perspective, it is easy to see that even small changes initiated by teachers may bring about significant changes in the environment (or the other way round) and, this can empower them for further action.

\section{Language Teaching Materials and Teacher Agency}

One of the most apparent ways in which language teachers enact agential roles is when they work with teaching materials, especially with ones that are prescribed to be used by educational authorities. As Bosompem (2014, p. 106) says, "[al]though the classroom teacher is the direct user of the books, selection usually goes beyond them to involve the Ministry of Education, institutional and departmental heads". In fact, teachers experiencing materials being "imposed on them from above" (Thornbury \& Meddings, 2009, p. 86) is a general practice often used as a means of 'quality control' by educational administration, or when new teaching methodologies are introduced. However, this does not necessarily lead to changes for the better or changes in practice at all (Nur, 2003).

When teachers need to use materials that they have not selected for their learners, it is inevitable that there will be a misfit between the users and the textbooks. This is, of course, experienced even when teachers have the freedom to select their own resources (Harmer, 2007; McDonough, Shaw, $\&$ Masuhara, 2012). Therefore, it is necessary for teachers to make changes in the materials (Edge \& Garton, 2009), and adaptation is the most commonly used practice during which texts, tasks, or activities are modified to meet teachers' and learners' needs.

There are many different techniques for teachers to adapt language learning materials and Tomlinson and Masuhara (2004) summarize them into three broad areas: plus, minus, and zero. When teachers use techniques that fall into the plus category, e.g. addition, expansion, they add something more to the existing materials. When techniques in the minus category are used, e.g. deletion, subtraction, then something is taken away, either in difficulty level, length of text, the activity itself, etc. Finally, techniques in the zero category, e.g. modification, replacement, etc. do not add to or delete from the materials; they modify them with new instructions, or by changing how they are supposed to be performed (individual work turned into pair work).

Yet, changing officially prescribed teaching materials is, as Priestley et al. (2015) pointed out, may prove to be a risky business. Whether teachers decide to do so, and thus exercise a higher level of agency, or choose to follow whatever the material tells them to do, is the focus of this present paper. More specifically, we will address the following research questions (RQ):

RQ1: To what extent do English Language (EL) teachers in rural Sarawak consider prescribed language teaching materials appropriate for their learners? 
RQ2: What reasons do they have for the adaptation - or lack of - of the prescribed materials?

RQ3: In what ways do they exercise agentive roles, if at all, in the adaptation of teaching materials?

\section{Method}

\section{Research Context}

The study was carried out in rural Sarawak, Malaysia, in a setting with multicultural and multilingual communities. The standard Malaysian curriculum is used in schools that are run and maintained by the federal government. Therefore, the medium of education - except for foreign languages - is Bahasa Malaysia. Despite the best of efforts, equality and equity are not always achieved in primary and secondary education throughout the state although "addressing socioeconomic differences is central to the current macro-planning in the highly publicised Malaysia Education 2013-2025 Blueprint" (Hall, 2015, p. 153). Some schools, especially those in rural areas, are without clean running water and electricity, while others are practically inaccessible in the dry season when the water level in the rivers - the main thoroughfare in some parts of the state - is low.

It is against this backdrop that the Malaysian Ministry of Education in 2018 introduced and made compulsory across all primary and secondary schools the use of two textbook series by Cambridge University Press: Super Minds and Pulse (Chin \& Rajaendram, 2017). These textbooks were written for an international audience and therefore may lack relevance in contexts where the socioeconomic conditions of the users are not reflective of the middle-class standards the materials portray. This raises serious questions about the appropriateness of the textbooks in the rural Sarawak context.

\section{Research Instruments}

Two instruments were used in the study: a mixed-methods online questionnaire and in-depth interviews with selected participants. The questionnaire elicited some demographic information about the teachers together with factual and interpretive information about the context in which they worked. It also asked them to evaluate the Super Minds 2 textbook (Puchta, Gerngross, \& Lewis-Jones, 2012) they were using in terms of the major language skills/areas and also whether it is culturally relevant and appropriate for their learners. Furthermore, it probed if they needed to adapt or supplement the material with other resources.

The in-depth, structured interviews were conducted over a video conferencing application, Zoom, and lasted about 45 minutes; they were transcribed for coding purposes. The interview questions were written according to Sealey and Carter's (2004) five broad areas of teacher agency: selfconsciousness, reflexivity, intentionality, cognition, and emotionality. Therefore, the following areas were probed within the context of materials exploitation: 
1. awareness of the conditions in which they work, e.g. how the context can enable or limit their capacity to act professionally;

2. the ability to reflect and evaluate past experiences in order for better planning and improved future action;

3. being motivated for change and making plans accordingly;

4. the ability to think logically about consequences of present and future action;

5. having positive feelings towards change and action.

\section{Research Participants}

A non-probability voluntary response sampling method was used to recruit participants to fill in the online questionnaire. The only criteria for participation were that respondents should teach English and they should work in a government primary school in rural Sarawak. Forty-five teachers responded to the call from a variety of schools. The average number of students in their schools was one hundred and sixty eight, with some schools over three hundred ninety pupils, whereas the smallest school had only twelve enrolled students. Only 8 of the teachers were nonoptionists, which means that they had not received any training in English language teaching. These teachers were assigned to teach English due to the lack of trained practitioners.

Three teachers were selected for the in-depth interview by purposive sampling. The selected teachers were all trained English language teaching professionals with a reputation of being excellent teachers. This fact was testified by awards they had received during their relatively short teaching careers (3-6 years) and their role in professional social media circles. The reason for selecting these teachers was twofold. Firstly, it was important to investigate if highly capable teachers were able to enact agentive roles in the context of rural Sarawak as it would indicate whether this would be feasible for the average teacher population. In other words, if these teachers suggested that they were not empowered to make changes in the materials they used, it could be assumed that other teachers would face the same problems. Secondly, understanding the reasons for their materials adaptation processes would allow a glimpse into how teacher agency is motivated and practiced in the state. All interviews and questionnaire responses were anonymized to protect the participants' identity. Teachers in the study are referred to by a number and the letter T, e.g. T21. The third person plural (they) is used in the analysis of the teacher interviews to hide the participants' gender and make it more difficult to identify them.

\section{Data Coding and Analysis Procedures}

The questionnaire data were examined through both quantitative and qualitative means. Basic descriptive statistics were used to provide a background for the interpretation of the quantitative data, e.g. satisfaction level with the textbook. The qualitative data from the questionnaire and the interview data were coded by using NVivo 12. In the first cycle, open or thematic coding (Saldaña, 
2009) was used to identify major themes or topics. This was followed by a priori coding based on Sealey and Carter's (2004) categories, and pattern coding during which existing categories of codes were expanded and collapsed to offer a better understanding of the data.

\section{Results}

\section{Appropriateness of Prescribed Materials in Rural Contexts}

To answer RQ1, i.e. "To what extent do EL teachers in rural Sarawak consider prescribed language teaching materials appropriate for their learners?" data from the questionnaire will be used.

Generally, teachers were not completely satisfied with the prescribed teaching material. They considered the textbook acceptable, giving an average of 2.7 points on a 4-point Likert scale (1very poor; 2- poor; 3-good; 4- very good). Interestingly, there was a slight difference between trained and non-trained language teachers' views as shown in Figure 1:

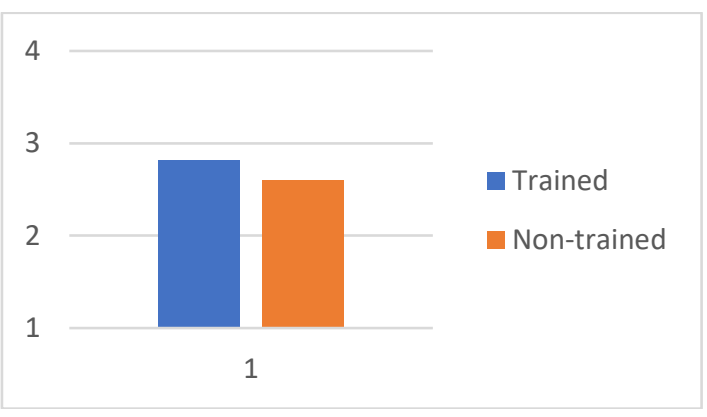

Figure 1.0. General Satisfaction with Super Minds 2

One possible explanation for this might be that non-trained teachers may expect more guidance from the textbook as they may lack the methodological know-how necessary to successfully use the material in the way it was intended.

There is a similar difference when individual language skills/areas in the book are examined; nontrained teachers seem to be less satisfied than their trained colleagues (see Figure 2). 


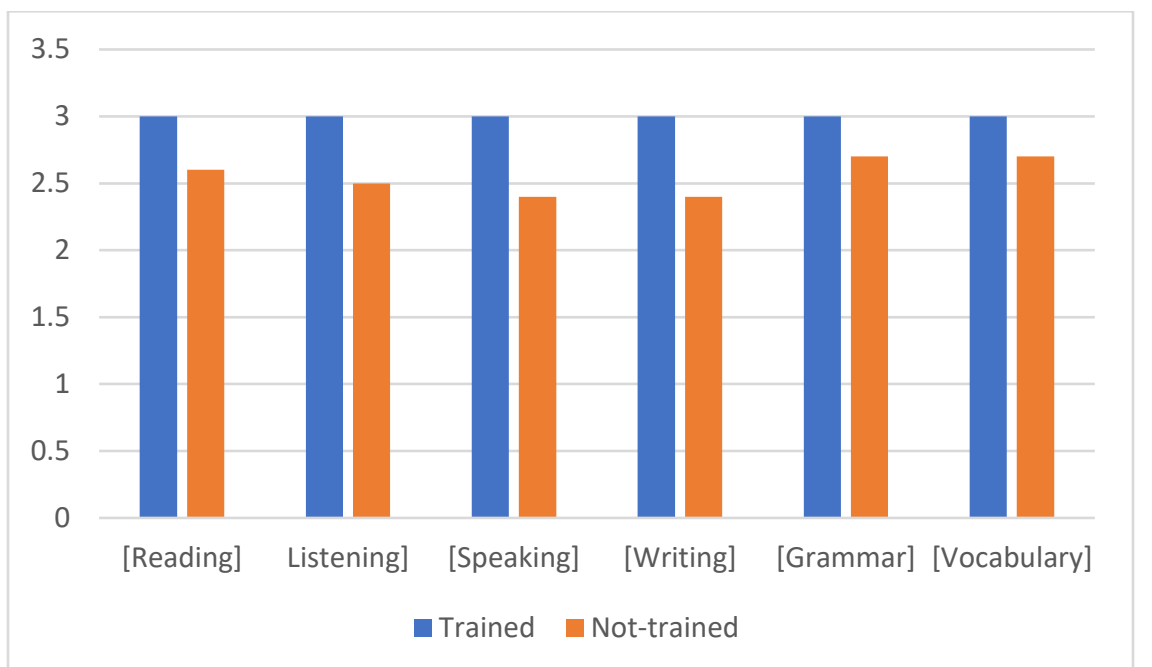

Figure 2.0. Teachers' Satisfaction with Regards to the Different Language Skills/Areas in the Material

As opposed to the earlier materials, the new textbook presents language in an integrated way where language skills, vocabulary, and grammar are taught in a meaningful context. This may go against the examination-oriented teaching methods where the language was taught in a compartmentalized manner. That 'teacher friendly' arrangement simplified the tasks that were needed to be performed in the classroom. Compared to that, teachers using the new textbook faced a more challenging task. As T48 (trained) said in the interview:

[The new textbook] is very complicated. Grammar components are everywhere. But in the previous textbook everything was well arranged. We knew that on this page you teach about grammar. The next page we were teaching about reading, the following one teaching about writing. But this page [showing actual book] they didn't tell you which page is teaching which skill.

When a trained English language professional sees the materials in this light, then using the textbook may be a daunting task for an untrained language teacher. For them, the isolated, examoriented practice of drilling and decontextualized practice - often found in older materials - would perhaps give more confidence and security. The uncertainty of how to exploit this 'new' material was also mentioned by others: "Quite difficult for teacher to do lesson plan as there is no guidance provided" (T18 - trained).

The reasons for the relatively low satisfaction are also connected to the students' language levels which are deemed to be either below or higher than the level the material offers, and the lack of cultural relevance.

- Pupils in rural area are very weak in English... then, comes this type of book that we must use in the classroom... struggled enough to explain to them (T19 - trained)

- The learning contexts for the new Super minds book do not suit the pupils especially in rural area (T2 - trained)

- Language used is not too difficult (T2 - trained) 
- Some of the words, phrases, sentences are too difficult for student as it is not their 1st and 2nd language (T4 - not-trained)

One trained teacher (T16) also remarked that the material is not helpful for preparing the students for their primary school leaving exam (UPSR): "Students only know some of the input and sometimes it doesn't help them in their exam especially UPSR." This was echoed by others as well, for example by T48 who said in the interview:

I follow the book page by page, but only after I have taught all the six tenses. The six tenses for me is a must, because I always believed that if the students manage to master these kinds of tenses then when they absorb new vocabulary they can use this vocabulary to write more correct sentences. I managed to prove this when in 2018 I managed to break the school record by [...] having a 100\% passing rate at the UPSR $[\ldots]$ so I try to use my own method [...] even though we are provided with a scheme of work, to be honest, I don't even follow it.

\section{Materials Adaptation}

Since the teachers were not fully satisfied with the materials, answering RQ2 is relevant: "What reasons do they have for their adaptation - or lack of - the prescribed materials?" In order to look into this first, we need to examine what areas of the textbook they deem necessary to adapt.

There is a slight difference, again, in the answers of trained and non-trained English teachers, as shown in Figure 3 below.

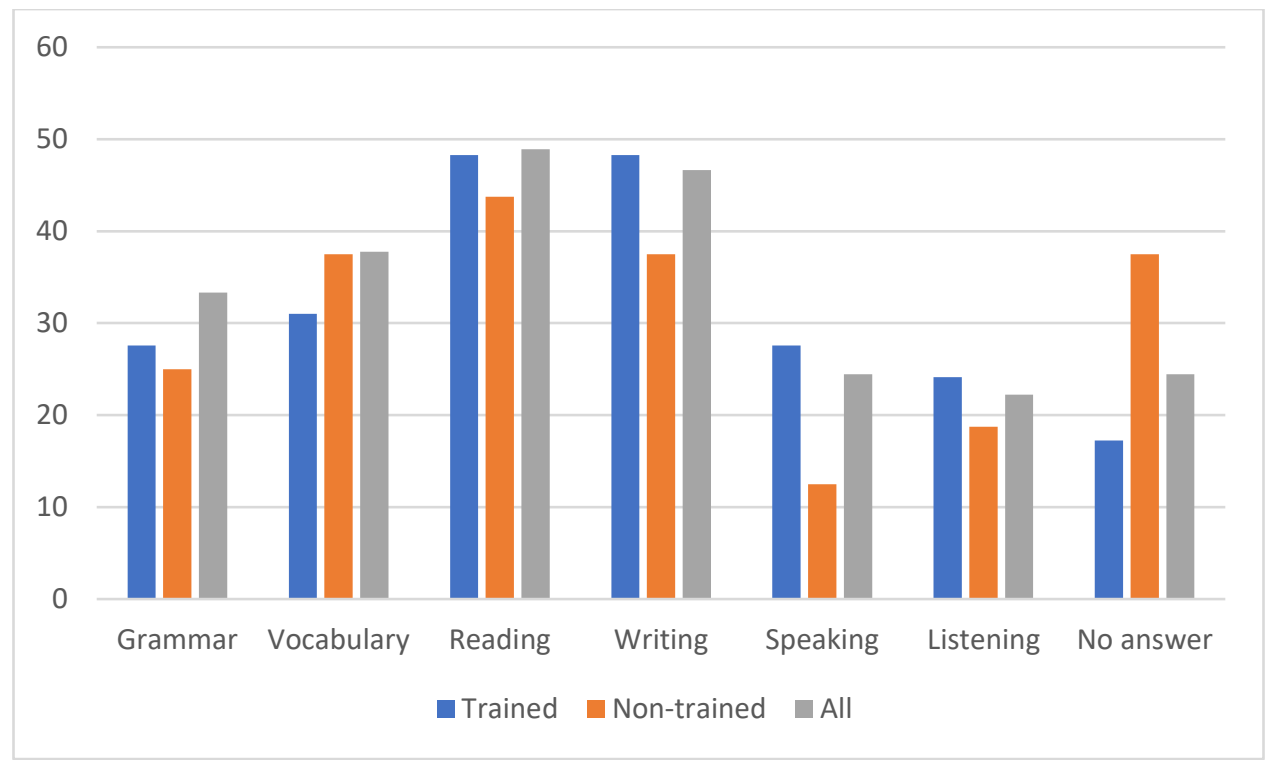

Figure 3.0. Areas of the Textbook Teachers Adapted to Fit Learners' Needs (in \%).

The figure shows that the most adapted area of the textbook is the reading skills development. Most probably teachers find the texts presented in the material unsuitable for their learners, as testified by the explanations they offered. T36 explains: "Some of my students are very poor. They 
never even go to the town. I need to explain about the bus, public phone and even the ATM". Therefore, some of the topics presented in the reading texts not only challenge learners linguistically, but they also struggle with understanding concepts that are alien in their own mother tongue(s) or cultural context.

It is also interesting to note that it is only in the area of vocabulary where non-trained English teachers do more adaptations than their trained colleagues. It is possible that they prefer areas where they feel in more control of the language and the content being taught than in areas where students could exercise more choices (e.g. in speaking). Furthermore, skills that are more prominently featured in the examination seem to receive more attention when it comes to materials adaptation. Many teachers (e.g. T17, T18, T23, T26, etc.) pointed out that input and activities in the textbook are 'not enough' for their learners. Yet, at the same time, they also lamented the weak language abilities of their learners. As one non-trained teacher put it, "[s]tudents' vocabulary is weak. They need guidance in actions or dual language to understand especially text form" (T39). This and similar comments perhaps suggest that teachers in the rural areas prefer exam-specific instructional methods and the use of the mother tongue in the lesson as a means of language instruction.

\section{Teacher Agency and Materials Exploitation}

Finally, it is also worth pointing out that almost one-quarter of all teachers (24.4\%) do not feel the need to adapt their materials, perhaps because they either lack the technical know-how, have no other resources, or do not feel empowered to do so. This takes us to answer RQ3, "In what way do they exercise agentive roles, if at all, in the adaptation of teaching materials?" In order to answer the question in a systematic manner, Sealey and Carter's (2004) five broad areas of teacher agency have been used in the data analysis: self-consciousness, reflexivity, intentionality, cognition, and emotionality.

All three teachers showed high levels of self-consciousness and also consciousness of the limitations they faced in terms of the scarcity of resources, the imposed policies and administrative rules, and their own professional capabilities as language teachers.

Perhaps what helped them most in analysing their situations and find possible solutions to the problems they faced was their ability of reflection. They expressed both the need and the usefulness of systematic reflection on their work and the keeping of notes for further thinking and action. However, interestingly, they all went about this practice in their own individual ways. T46 believed in the beneficial effects of learning communities and was a proponent of peer observations and critiquing video recordings of lessons that could be either analysed alone or discussed together with colleagues. T47 did not only rely on colleagues in his immediate work vicinity; they were part of a social networking group that was set up at the end of their teacher training days. In this group of 14 people from the same batch of teacher trainees, members shared about their teaching, both successes and failures, regularly on a weekly basis. Apart from this, they also used the reflection part of the official lesson plan template and a private teaching journal which also served as a record of the students' life events, personal information that can be incorporated to personalize learning. To illustrate this, they explained: 
For example, Victoria will have a new baby sister next week, so I will jot this down and reflect on how I can connect this into my next lesson [...] so at one point this file has become a diary of my learner. It is really good because it helps me understand my kids more and they also see me as someone who is really interested in them (T47).

T48 also used a variety of reflection tools and platforms, including online social media and personal diary/ lesson notes. In sum, reflection in- and on-action helped the teachers gain a better understanding of their contexts and plan for future action.

Of course, action is only possible if there is the right amount of motivation that drives it. During the interviews, all three teachers showed high levels of intentionality. They commented that what motivates them in changing the teaching materials is that they felt it did not meet their students' needs, therefore, adaptation was inevitable to create a meaningful learning experience in the classroom. T46 explains:

Most of the time I need to adapt the context. We need localized context. So, the Super Minds book it is serving global context so for us in the rural [areas] we need to localize it. So that [the students] can understand it better. For example, there is a unit about food, right? We can introduce all the food, vegetables from the local farm [...] to introduce something which is actually in the surrounding. It is useful for them.

It is interesting to note, however, that the thinking behind materials adaptation, i.e. the cognition teachers practiced, was distinctively different in each case. Whereas all three teachers were aware of the possible repercussion they might face resulting from deviation from the prescribed materials and teaching plans, they gave completely different reasons for doing it. T46, for example, said that working in a remote jungle school had one significant advantage over teaching in an urban school: there is hardly ever any inspection of the school or the teachers. In their 6 years of service, they had never been observed by the Department of Education that does regular checks on teachers in order to ensure quality education in the state.

T47 had a different reasoning for abandoning complete sections of the prescribed textbook or adapting and changing significant parts of it. They were explaining that professionalism, knowledge, and confidence is what one needs when they divert from a scheme of work set by administrators who had no knowledge of the particular local context and the students they had to work with. They claimed: "When you have your justifications and if you are brave enough to talk about it and confident that you are doing the right thing, then you have to do it. I do stuff because I know I am right and I can defend myself'.

Finally, T48's reasoning why they completely ignored the prescribed textbook and the scheme of work was different from the other two. They argued that as long as the students do well in the primary school leaving exam, or in the interim tests, educational authorities would not be bothered about how the results were produced. The passing rate for T48 is indeed exceptional; all of their students (100\%) manage to pass the UPSR exam, an achievement very rarely heard of in the context of rural, minority learners. Of course, such a feat comes with a price. While the other teachers' students seemed to enjoy the lessons they participated in, by T48's own admission their lessons might not be interesting to all the learners. "In terms of boring or not, even if the students 
don't tell me face-to-face, I see it in their body language [...] it is difficult to find something that fits their interest." It is interesting to note that T48 does not seem to consider their own examoriented teaching methods as the source of the lower levels of engagement; they think it is the students who are difficult to motivate.

\section{Discussion}

The major findings of the study indicate that the government assigned textbooks for English may not be appropriate learning resources in rural Sarawak, where the cultural and economic divide between the contexts presented by the materials and the learners' own social realities seem worlds apart. This is further intensified by the lack of material resources and/or professional training opportunities teachers could use to modify the texts and tasks they need to work with. Yet, despite the difficulties, (some) teachers feel empowered to change - even completely depart from - the textbooks to design lessons they believe benefit their students.

All interviewed teachers emphasized that their material adaptation was motivated by the desire to meet their learners' needs. They also agreed that they could make whatever changes they thought necessary in the prescribed materials; thus, their agentive capacity was high. However, they gave very different reasons why this was possible in their work contexts. T46 acknowledged that the lack of control by the Department of Education enabled them to make changes without the fear of repercussions. T47 was convinced that as long as they could provide a firm and professionally sound explanation for their classroom decisions, they were allowed to adapt the material to benefit the learners. Finally, T48 believed that the end justifies the means; the fact that their learners all passed the UPSR exam would entitle them to make any change they wanted. They were convinced, perhaps rightly so, that educational administration was only interested in examination results (what) and not the actual teaching (how) practices in schools. Questions about how teachers work are only asked when the results do not conform to expectations.

Looking at the results from the perspective of teacher agency, Goller and Paloniemi (2017) concepts of individual capacity and action should be revisited. The data indicate that all interview participants had the capacity to control their professional lives and they acted accordingly in order to improve their (and to some extent their learners') quality of life (Bandura, 2001) in the schools they were teaching. Whether this is true only for these well-respected professionals or it is a general trend among teachers in rural Sarawak is unknown, although the data show that $24.4 \%$ of respondents did not feel the need to adapt the textbook. This may be a sign that capacity and action may not be a general feature for all teachers in the state.

Furthermore, the importance to look at teacher agency within the context where it is enacted was highlighted by our study. Biesta and Tedder (2007) argued that agency is enabled by the context in which teachers act, rather than it simply 'happening' in there. The data show that although the educational and social constraints, i.e. lack of resources, rigid guidelines and examination structure, economically and socially marginalized learner population, have been the same for all interviewees, their interpretation of their situation and context enabled them to act independently, enacting their professional decisions (Eteläpelto, Vähäsantanen, Hökkä, \& Paloniemi, 2013). This was done in full awareness that they went against officially articulated policy and regardless of the possible retributions they might have faced. 
Yet, the difference in their motivation that enabled their agentive roles indicates that teacher agency is an emergent phenomenon (Sealey \& Carter, 2004) that is based on a multitude of contextual and internal factors. Small changes in this educational ecosystem could easily have a large impact on how teachers act or do not act since no action might indeed be one indication of teacher agency. For example, should T48's motivation to 'produce' a 100\% pass rate at the exam suffer a temporary slump, or should the current examination structure change to be more aligned with the new materials, or concerns for student engagement arise, they may follow the teaching materials more closely and thus embrace sponsored professionalism (Leung, 2009). There is evidence to believe that the same would apply to the other two interviewees, T46 and T47, who chose to enact their professional beliefs for completely different reasons. One was encouraged by the lack of control (T46), which could easily change by the introduction of a visit by a school inspector, whereas the other (T47) may lose their confidence in their professional theories, should they be confronted by an administrator equally well-informed by educational research. After all, there is no one right way of teaching.

The above argument does not aim to minimize the importance of teacher agency. Quite the contrary; it tries to highlight the need to create an educational ecosystem where all agents (teachers, administrators, examination experts, even students and parents) are valued and active contributors. A system where difference of opinion is not shunned, but appreciated and serves the dynamic growth and well-being of the whole. In fact, difference is a must, not only in terms of teacher agency to emerge, but also for the development of individual teacher identities that are shaped by past and present experiences, i.e. the feedback from the system that allows actors to be enriched both personally and professionally (Priestley, Biesta, \& Robinson, 2015).

\section{Conclusion}

In this paper, we examined teacher agency in the broader context of materials exploitation and looked at how English language teachers in rural Sarawak enact agentive roles when they worked with an officially prescribed textbook series, Super Minds. Our findings showed that teachers are generally not satisfied with the textbook because they consider it: a) alien to the local cultural context, b) linguistically challenging for most learners, or c) linguistically too easy and thus misaligned with the testing and examination practices.

The data also showed that most teachers felt the need to adapt the materials to fit their learners' specific needs. Yet, what empowered them to modify the textbook and divert from the official scheme of work depends on their own professional and individual interpretation of the context in which they work. One of the major findings of the study points to the interaction of individual capacity, informed action, and the context which enables teacher agency to emerge as a complex and dynamic phenomenon. Therefore, minor changes in the teaching ecosystem may bring about significant changes which could either support or suppress teachers' autonomy and motivation to enact their professional values in the classroom. 


\section{References}

Allwright, D. (1981). What do we want teaching materials for? ELT Journal, 36(1), 5-18.

Archer, M. (2003). Structure, agency and the internal conversation. Cambridge: Cambridge University Press.

Bandura, A. (2001). Social cognitive theory: An agentic perspective. Annual Review of Pychology, 52(1), 1-26.

Biesta, G., \& Tedder, M. (2007). Agency and learning in the lifecourse: Towards an ecological perspective. Studies in the Education of Adults, 39(2), 132-149.

Borg, S. (2006). Teacher cognition and language education: Research and practice. London: Bloomsbury Publishing.

Bosompem, E. G. (2014). Materials adaptation in Ghana: Teachers' attitudes and practices. In S. Garton \& K. Graves (Eds.), International perspectives on materials in ELT (pp. 104-120). Basingstoke: Palgrave Macmillan.

Bouchard, J. (2017). Ideology, agency, and intercultural communicative competence. Singapore: Springer.

Cheah, Y. M. (1988). The examination culture and its impact on literacy innovations. Language and Education, 12(3), 192-209.

Chin, C., \& Rajaendram, R. (2017, 5 October). Only imported English textbooks from next year. The Star. Retrieved 17 January, 2021 from https://www.thestar.com.my/news/nation/2017/10/05/only-imported-english-textbooksfrom-next-year-move-part-of-reform-to-ensure-international-proficien

Edge, J., \& Garton, S. (2009). From knowledge to experience in ELT. Oxford: Oxford University Press.

Eteläpelto, A., Vähäsantanen, K., Hökkä, P., \& Paloniemi, S. (2013). What is agency? Conceptualizing professional agency at work. Educational Research Review, 10, 45-65.

Gleick, J. (1987). Chaos: Making a new science. New York: Viking Penguin.

Goller, M., \& Paloniemi, S. (Eds.). (2017). Agency at work: An agentic perspective on professional learning and development. Cham: Springer.

Hall, J. S. (2015). A past before a blueprint: Malaysia's challenges in English language teaching. In R. Stroupe \& K. Kimura (Eds.), ASEAN integration and the role of English language teaching (pp. 149-168). Phnom Penh: IDP Cambodia.

Harmer, J. (2007). How to teach English. Harlow: Pearson.

Holliday, A. (2015). Native-speakerism: Taking the concept forward and achieving cultural belief. In A. Swan, P. Aboshiha \& A. Holliday. (Eds). (En)countering native-speakerism (pp. 11-25). London: Palgrave Macmillan.

Imants, J., \& Van der Wal, M. M. (2020). A model of teacher agency in professional development and school reform. Journal of Curriculum Studies, 52(1), 1-14.

Kiss, T., \& Mizusawa, K. (2018). Revisiting the pedagogy of multiliteracies: Writing instruction in a multicultural context. Changing English, 25(1), 59-68.

Kiss, T., \& Rimbar, H. (2017). Unity in diversity: How teachers address issues of culture in locally produced EFL material. Folio, 18(1), 4-11.

Larsen-Freeman, D. (1997). Chaos/complexity science and second language acquisition. Applied Linguistics, 18(2), 141-165.

Larsen-Freeman, D. (2002). Language acquisition and language use from a chaos/complexity theory perspective. In C. Kramsch (Ed.), Language acquisition and language socialization: Ecological perspectives (pp. 33-46). New York: Continuum.

Leung, C. (2009). Second language teacher professionalism. In A. Burns \& J. Richards (Eds.), The Cambridge guide to second language teacher education (pp. 49-58). Cambridge: Cambridge University Press.

McDonough, J., Shaw, C., \& Masuhara, H. (2012). Materials and methods in ELT: A teacher's guide (3rd ed.). Oxford: John Wiley \& Sons. 
Nur, C. (2003). English language teaching in Indonesia: Changing policies and practices. In W. K. Ho \& R. Y. L. Wong (Eds.), English language teaching in East Asia today: Changing policies and practices (pp. 163-172). Singapore: Eastern Universities Press.

Priestley, M., Biesta, G., \& Robinson, S. (2015). Teacher agency: what is it and why does it matter? In R. Kneyber \& J. Evers (Eds.), Flip the system: Changing education from the bottom up (pp. 1-11). London: Routledge.

Puchta, H., Gerngross, G., \& Lewis-Jones, P. (2012). Super minds level 2: Student's book. Cambridge: Cambridge University Press.

Sealey, A., \& Carter, B. (2004). Applied linguistics as social science. London: Continuum.

Saldaña, J. (2009). The coding manual for qualitative researchers. London: SAGE Publications Ltd.

Thornbury, S., \& Meddings, L. (2009). Teaching unplugged: Dogme in English language teaching. Peaslake: DELTA Publishing.

Tomlinson, B. (2012). Materials development for language learning and teaching. Language Teaching, 45(2), 143-179.

Tomlinson, B., \& Masuhara, H. (2004). Developing language course materials. Singapore: SEAMEO.

Van Lier, L. (2010). The ecology of language learning: Practice to theory, theory to practice. Procedia-Social and Behavioral Sciences, 3, 2-6. 